Check for updates

Cite this: RSC Adv., 2017, 7, 44696

Received 3rd July 2017

Accepted 4th September 2017

DOI: $10.1039 / c 7 r a 07349 f$

rsc.li/rsc-advances

\section{Characteristics of toluene decomposition and adsorbent regeneration based on electrically conductive charcoal particle-triggered discharge}

\begin{abstract}
Gang Xiao, Weiping Xu, (iD Zhongyang Luo (iD * and Hua Pang
Volatile organic compounds (VOCs) are detrimental to human health, and are also among the most important causes of secondary particulate formation and ozone pollution. The combined method of adsorption and non-thermal plasma has been attracting increasing interest due to its efficient energy consumption. This study aims to explore a new approach for removing gaseous toluene using electrically conductive charcoal (ECC) as an adsorbent and to trigger discharge. ECC was prepared from biomass and had a low electrical conductivity of $0.354 \Omega \mathrm{cm}$ and an abundant porous structure with a surface area of $717 \mathrm{~m}^{2} \mathrm{~g}^{-1}$. After toluene adsorption (53-217 $\mathrm{mg} \mathrm{g}^{-1}$ ), adsorbent particles were fluidized with oxygen-containing gas and subjected to high voltages (17.4-26.3 W). Micro-arcs formed between the fluidized ECC particles, which led to toluene desorption and decomposition while the ECC was regenerated. The desorption was facilitated compared to thermal desorption. The adsorbed toluene was almost completely desorbed, and $59.23 \%$ of toluene was decomposed at one time. Almost no ozone or nitrogen oxides were found in the gas produced from decomposed toluene. Higher adsorption and discharge power were beneficial for decomposition capacity, but the former was limited by short residence time. The adsorption capacity of ECC increased by $16.4 \%$ after four cycles. A design was presented for continuous treatment of VOC pollutant without the emission of VOCs.
\end{abstract}

\section{Introduction}

Among gaseous pollutants, volatile organic compounds (VOCs) are detrimental to both human health and the environment. Many VOCs are carcinogenic, causing serious health problems ${ }^{\mathbf{1}}$ and high levels of exposure can lead to paralysis of the nerve centre, nausea, muscle weakness, etc. Apart from the direct harmful effects caused by VOCs, indirect air pollution has also received considerable attention.

China is facing critical particulate pollution. ${ }^{2}$ The concentrations of $\mathrm{PM}_{2.5}$ in 74 major Chinese cities have exceeded the Chinese pollution standard of $75 \mu \mathrm{g} \mathrm{m} \mathrm{m}^{-3}$ for $40 \%$ of days in January, 2017. ${ }^{3}$ A large portion (51-77\%) of $\mathrm{PM}_{2.5}$ mass consists of secondary species, i.e., secondary aerosols. Controlling secondary aerosol precursors is also becoming a major concern. VOCs play an important role in the formation of secondary aerosols through a series of gas-to-particle conversion paths, ${ }^{4}$ as shown in Fig. 1. Ozone pollution is also becoming increasingly severe due to photochemical smog, which is formed in the presence of VOCs. The 13th Chinese Five-Year Plan stated that total VOC emissions should be reduced by at least $10 \%$ by $2020 .^{5}$ Reducing VOC emission in China is going to be a critical issue over the next few years.

State Key Laboratory of Clean Energy Utilization, Zhejiang University, Hangzhou 310027, China. E-mail: zyluo@zju.edu.cn; Tel: +86-571-87952440
Toluene is widely used as a solvent and raw material in chemical industries, pharmaceutical factories, and painting industries. Toluene plays an important role in the VOCs emission in China. ${ }^{6,7}$ It was estimated that toluene covered $6.2 \%$ of the total industrial VOCs emission in China in 2013..$^{7}$ Toluene has been a common VOC used for investigation in previous studies on DBD, ${ }^{8-10}$ gliding arc discharge,${ }^{11,12}$ corona discharge..$^{13,14}$ It was selected as a pollutant for testing in this study.

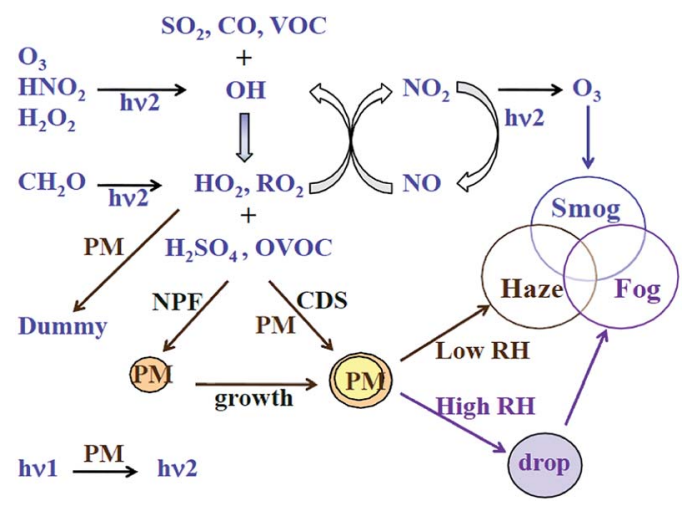

Fig. 1 The most important chemical processes for forming photochemical smog and haze-fog ${ }^{4}$ (PM: aerosol particles, NPF: new particle formation, CDS: the condensation of trace gases on aerosol surfaces). 
Adsorption is an effective method of removing VOCs. It has been reported that the market share of adsorption was $38 \%$ of VOC treatment in China, based on 330 VOC treatment cases. ${ }^{15}$ Porous carbonaceous materials, such as activated carbon, are widely used because of their abundant porous structures and high adsorption capacity. Once saturated, the adsorbents become hazardous residues that are then disposed or incinerated. This causes secondary pollution, but replacing carbonaceous materials with a new adsorbent is not cost-effective. From energy saving and economic point of view, regenerating the adsorbents and decomposing adsorbed VOCs would be preferable.

Of the numerous solutions to this problem, combining an adsorption method with non-thermal plasma (or sequential treatment) has been widely investigated due to its efficient energy consumption and cost-effectiveness. ${ }^{\mathbf{1 6 - 2 1}}$ This approach could treat a wide range of VOC pollutant concentrations. Sivachandiran et al. ${ }^{20}$ used a $\mathrm{TiO}_{2}$-based catalyst to adsorb isopropanol and then packed it in a dielectric barrier discharge (DBD) to remove isopropanol (IPA). They found that plasma regeneration of the IPA-saturated $\mathrm{TiO}_{2}$ surface led to simultaneous IPA desorption and mineralization. Mok et al. ${ }^{18}$ and Dang et $a l .{ }^{16}$ investigated DBD packed with $\gamma-\mathrm{Al}_{2} \mathrm{O}_{3}$ pellets via performing two sequential processes: toluene adsorption, followed by DBD oxidation. They found that adsorbed toluene was completely decomposed and ozone was the only by-product. Kuroki et $a .^{17}$ combined xylene adsorption by zeolite with decomposition by nonthermal plasma with gas circulation and compared two power sources with different frequencies. They reported that high frequency power increased energy efficiency; however, $\mathrm{NO}_{x}$ by-products were found to be generated. Zhao et $a{ }^{21}{ }^{21}$ investigated the removal of low-concentration formaldehyde from air using cycled storage-discharge (CSD), a plasma catalytic process, and used HZSM-5 impregnated with $\mathrm{Ag} / \mathrm{Cu}$ as both catalyst and adsorbent. They found out that the process had an extremely low energy cost and excellent humidity tolerance, with almost no secondary pollution. In summary, they focused on zeolite, $\mathrm{TiO}_{2}, \mathrm{HZSM}-5$, and $\mathrm{Al}_{2} \mathrm{O}_{3}$-based catalysts/ adsorbents loaded with heavy or transition metals, and almost all of the non-thermal plasma used DBD. These adsorbents have relatively low surface areas (such as $\sim 40 \mathrm{~m}^{2} \mathrm{~g}^{-1}$ for $\mathrm{TiO}_{2}$-based catalysts, ${ }^{20} \sim 230 \mathrm{~m}^{2} \mathrm{~g}^{-1}$ for $\mathrm{Al}_{2} \mathrm{O}_{3}$-based catalysts, ${ }^{18}$ $\sim 300 \mathrm{~m}^{2} \mathrm{~g}^{-1}$ for HZSM-5-based catalysts ${ }^{21}$ ), and thus their abilities for concentrating VOCs are limited. Most catalysts use transition or noble metals such as $\mathrm{Mn}$ or Ag. These are not renewable resources and the catalyst deactivation issue remains to be resolved. ${ }^{22,23}$ The adsorbents mentioned above are also not electrically conductive and when they are submerged in the discharge area, they act as packed materials. Discharge was generated via dielectric barrier discharge and was not directly triggered by the adsorbents; thus, upscaling of the reactor would be limited by dielectric barrier discharge.

Electrically conductive charcoal (ECC) that has excellent adsorption performance and electrical conductivity was suggested as an adsorbent and to trigger discharge. This type of adsorbent has a high surface area $\left(>700 \mathrm{~m}^{2} \mathrm{~g}^{-1}\right)$, and thus the concentration of VOCs could be highly promoted.
Carbonaceous adsorbents are cheap and renewable since they can be prepared from biomass, such as agricultural waste. Finally, when conductive adsorbent particles are in motion (for example, fluidized) and subjected to high voltage, microdischarge occurs between particles. At the points where the particles separate, current densities are extremely high (as much as $10^{4}$ to $10^{7} \mathrm{~A} \mathrm{~cm}^{-2}$ ). ${ }^{24}$ Arc discharge generated from the surface under an extremely intensive electric field leads to the formation of abundant reactive species, which could be a potential method for regenerating and decomposing adsorbed VOCs. The discharge area and the reactor could be scaled up more easily than those based on DBD. Based on this observation, this study investigated this approach and aimed to understand the mechanism. Discharge characteristics were presented to examine the arc formation process. The influence of factors on the desorption and decomposition of toluene were also investigated.

\section{Experimental setup}

\subsection{Preparation of granular electrical conductive charcoal} (ECC)

According to previous studies, the electrical conductivity of charcoal was related to its carbonization temperature. ${ }^{\mathbf{4 , 2 5}}$ To enhance discharge between particles, charcoal with lower electrical resistivity was prepared through high temperature carbonization. $\mathrm{CO}_{2}$-activation was conducted for abundance of porous structure.

Granular corncob, obtained from Shandong Gaotangtewei Technology Co., Ltd, was used as a precursor for ECC preparation. A corundum container with $15 \mathrm{~g}$ dried granular corncob (30-40 mesh) was put into the tube furnace. $\mathrm{N}_{2}$ (99.999\%) was added into the furnace at a flow rate of $500 \mathrm{~mL} \mathrm{~min}^{-1}$ for half an hour to create an inert atmosphere. After that, the heating program started and the flow rate was reduced to $100 \mathrm{~mL} \mathrm{~min}^{-1}$. The temperature increased at a speed of $5{ }^{\circ} \mathrm{C} \mathrm{min}{ }^{-1}$ from room temperature to $400{ }^{\circ} \mathrm{C}$ to produce a high yield of charcoal and then at $10^{\circ} \mathrm{C} \mathrm{min}^{-1}$ to $800{ }^{\circ} \mathrm{C}$ for less of an effect on the charcoal yield. The temperature was maintained at $800{ }^{\circ} \mathrm{C}$ for two hours for carbonization (the first hour) and $\mathrm{CO}_{2}$-activation (the second hour). During carbonization, the gas entering the furnace was still $\mathrm{N}_{2}$ at a flow rate of $100 \mathrm{~mL} \mathrm{~min}^{-1}$. During the $\mathrm{CO}_{2}$-activation period, the gas was changed to $\mathrm{CO}_{2}$ at a flow rate of 400 $\mathrm{mL} \mathrm{min}^{-1}$. Following this, the heating was stopped and the gas was changed back to $\mathrm{N}_{2}$ at a flow rate of $100 \mathrm{~mL} \mathrm{~min}^{-1}$ until the furnace was cooled to room temperature. The charcoal obtained was washed in boiled water for two hours to remove fine particles, and then dried at $135{ }^{\circ} \mathrm{C}$ for 12 hours. The particles were collected through a 40-60 mesh and stored in a desiccator. The ECC yield was about $22 \%$. The prepared material had a conductivity of $0.354 \Omega \mathrm{cm}$. The BET surface area of the ECC was $717 \mathrm{~m}^{2} \mathrm{~g}^{-1}$ with an average pore size of $2.054 \mathrm{~nm}$.

A general schematic of the experimental setup is presented in Fig. 2, including gas preparation, the reactor, power supply, power measurement system and analytical device. These are introduced separately, as follows: 


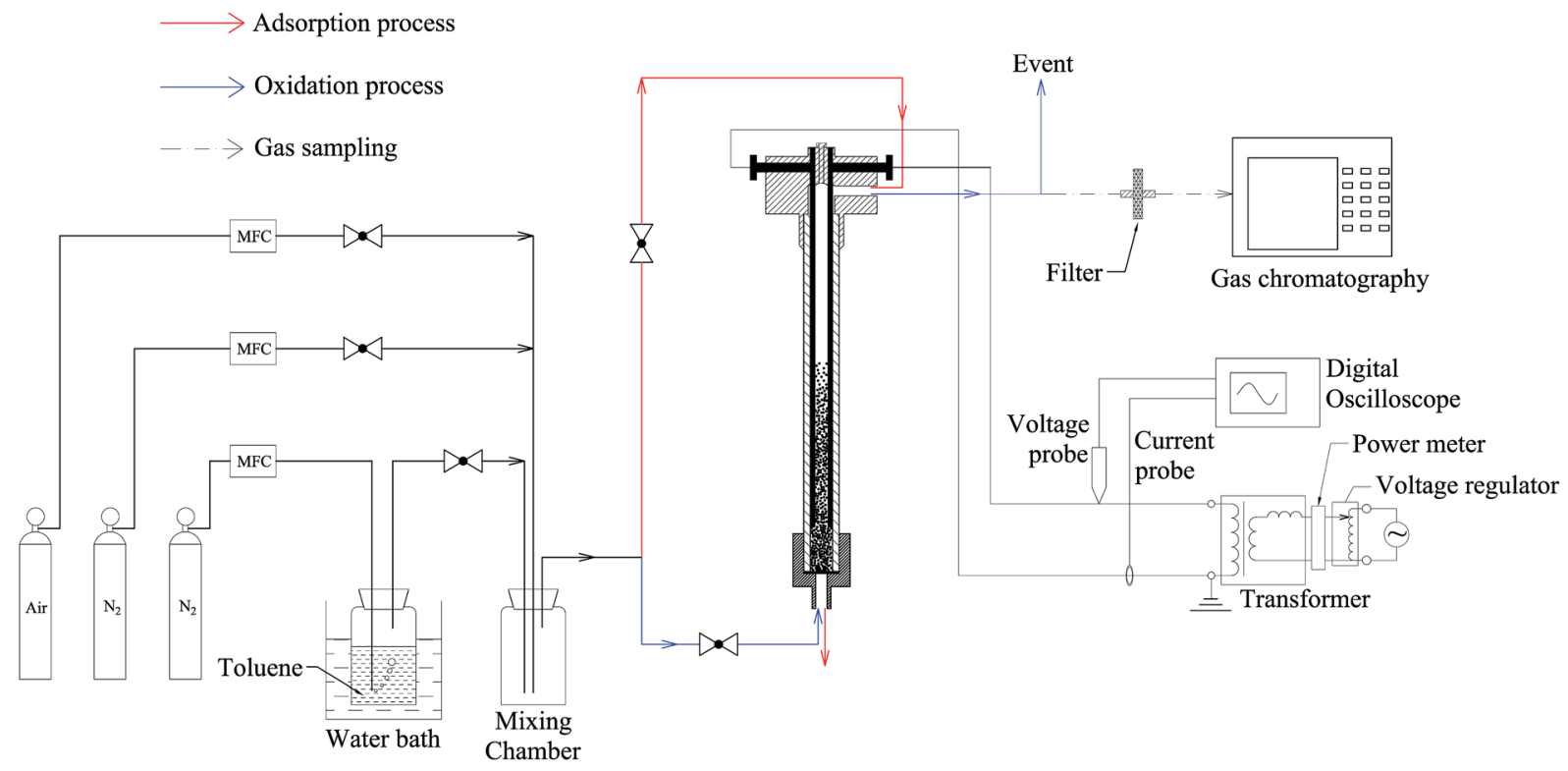

Fig. 2 The experimental setup.

\subsection{Gas preparation}

Toluene was generated by bubbling $\mathrm{N}_{2}$ through liquid toluene (HPLC grade), which was maintained at $30^{\circ} \mathrm{C}$ in a water bath. Gaseous toluene was diluted with $\mathrm{N}_{2}$ or air to a certain concentration in a mixing chamber. In the adsorption process, no voltage was applied. The gas mixture $\left(\mathrm{N}_{2}+\right.$ toluene) was introduced from the top and during the oxidation process, the gas mixture was changed to $\mathrm{N}_{2}+$ air injected from the bottom. The percentage of $\mathrm{O}_{2}$ was adjusted to $1 \%$, and all of the gas flow rates were controlled by a Mass Flow Controller (MFC, Sevenstar).

\subsection{Reactor configuration and power supply}

A detailed description of the reactor is presented in Fig. 3. It consists of a quartz tube $\left(d_{\text {in }}=10 \mathrm{~mm}, d_{\text {out }}=16 \mathrm{~mm}, L=\right.$ $250 \mathrm{~mm})$ and two parallel cylindrical electrodes $(d=2 \mathrm{~mm})$

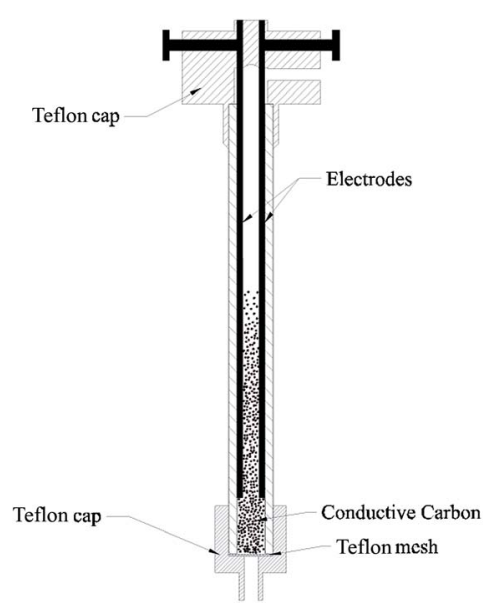

Fig. 3 Schematic of the reactor. made of stainless steel. The two ends of the quartz tube were covered by a Teflon cap. The electrodes were fixed inside the upper Teflon cap, with a distance of $6 \mathrm{~mm}$ between them. A Teflon mesh for holding ECC particles was placed at the bottom of the tube. To prevent the mesh from being damaged by discharge, the bottom of the electrode was $20 \mathrm{~mm}$ above the Teflon mesh and the input power was restricted.

The reactor was supplied with a high voltage transformer $(50 \mathrm{~Hz}, 500 \mathrm{~W})$. A voltage regulator was installed in the circuit to adjust output voltage $(0-60 \mathrm{kV})$. A power meter was installed at the transformer input to measure input power. An inductance was installed in the circuit between the regulator output and the transformer input to protect the transformer from excessive current.

\subsection{Power measurement and analytical device}

Voltage and current were measured using a high voltage probe (P6015A, Tektronix), a current probe (CP8030A, Shenzhen Zhiyong Electronics), and a digital oscilloscope (DPO2014B, Tektronix). The power waveform was obtained by multiplying the voltage waveform and the current waveform. Discharge power was calculated from four seconds of weighted averaged power (integrating the waveform with respect to $4 \mathrm{~s}$ and divided by 4$)$.

Gas chromatography (GC, Hangzhou Kexiao Chemical Equipment Co., Ltd.) was used to measure the concentration of toluene and was equipped with a flame ionization detector (FID). It was installed with an ATSE-30 capillary column. The column temperature was set at $90{ }^{\circ} \mathrm{C}$, and the split ratio was set at $5: 1$.

The oxidation product was collected in a Tedlar gas bag $(1 \mathrm{~L})$ and analyzed with a Fourier transform infra-red (FTIR) spectrometer (Nicolet iS50) with a resolution of $4 \mathrm{~cm}^{-1}$. It was equipped with a gas cell (Pike Technologies, optical path length 
$=2.4 \mathrm{~m}$ ). The entire equipment was operated in a sealed cover to avoid atmospheric interference. Before analysis, $\mathrm{N}_{2}$ (99.999\%) was introduced into the spectrometer to drive away the remaining gas in the gas cell for obtaining the background spectrum. Background spectrum before and after the sample analysis is shown in Fig. 4. No difference could be found, as shown in Fig. 4(b), indicating that there was no atmospheric interference. More than $500 \mathrm{~mL}$ of sampling gas was introduced and the spectrum of oxidation product was obtained. FTIR spectra were collected with 32 scans per spectrum. The spectra were compared with Standard Reference Database from National Institute of Standards and Technology (NIST) ${ }^{26}$ to identify the gas components.

The oxidation product was analysed using testo 350 gas analyzer (resolution and measuring range: NO (1 ppm, 0$400 \mathrm{ppm}), \mathrm{NO}_{2}$ (0.1 ppm, 0-500 ppm)). It was sampled with a built-in pump at a flow rate of $1 \mathrm{~L} \mathrm{~min}^{-1}$. It was measured at $20 \mathrm{~min}$ after discharge commenced (flow rate: $1.2 \mathrm{~L} \mathrm{~min}^{-1}, 1 \%$ $\mathrm{O}_{2}$, adsorbed amount: $217 \mathrm{mg} \mathrm{g}^{-1}$, input power: $175 \mathrm{~W}$ ). The measurement was continued for 10 minutes ( 1 scan per second).

\subsection{Measurement of equilibrium temperature of ECC}

Obtaining the temperature of the discharge zone on line by a thermal couple is very difficult because thermal couple's signal would be affected by arc discharge under a high voltage. Temperature at the top of discharge zone was measured with infrared thermometer (TECMAN TM900) during discharge ( $T_{\text {inf.ther }}$. After that, the high voltage power and gas flow were
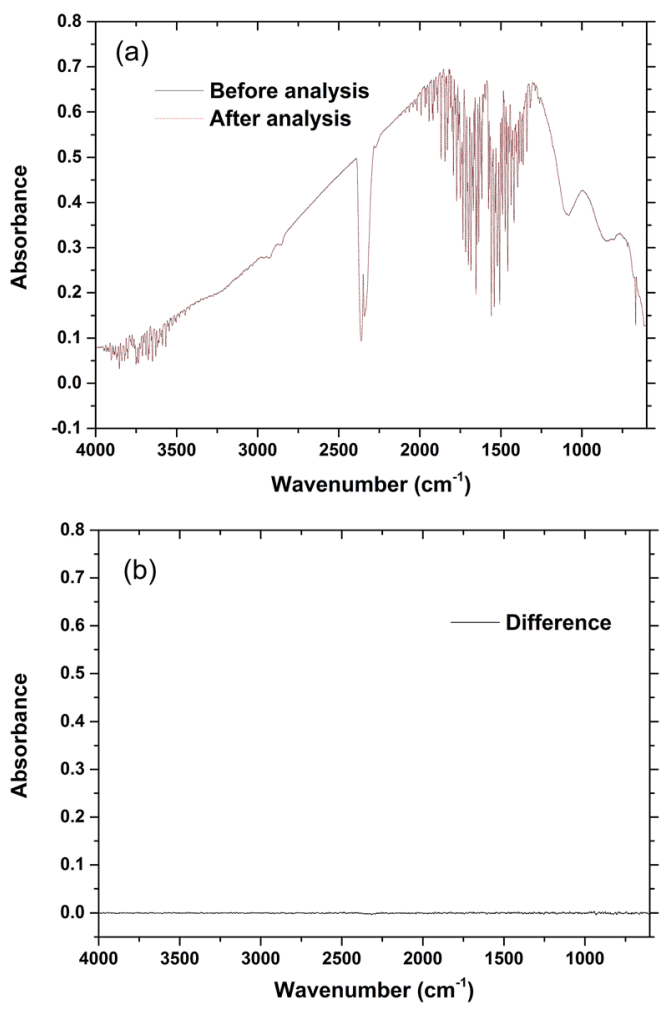

Fig. 4 Background spectra analysis. (a) Before (black line) and after (red line) the sample analysis, (b) difference between them. turned off simultaneously and a thermal couple was inserted into the centre of the particle bed within five seconds. The maximum value of the reading was obtained ( $\left.T_{\text {ther.coup }}\right)$. It was found that $T_{\text {inf.ther }}$ was in accord with $T_{\text {ther.coup }}$, as shown in Fig. 5. As a result, $T_{\text {inf.ther }}$ was used to represent the temperature of ECC during discharge.

\subsection{Experimental procedure}

There were three consecutive processes: the adsorption process (red line in Fig. 2), the oxidation process (the blue line in Fig. 2), and the thermal desorption process, as shown in Fig. 6 .

In the adsorption process, $1 \mathrm{~g}$ of ECC was put into the reactor. The gas mixture was set at a high concentration $(\sim 1300 \mathrm{ppm})$ to reduce adsorption time, with a flow rate of

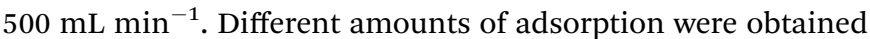
through adjusting the adsorption time. The adsorption amount was obtained through the difference between the mass before and after adsorption.

Following the adsorption process, the reactor was flushed with $\mathrm{N}_{2}\left(1.2 \mathrm{~L} \mathrm{~min}^{-1}\right)$ for one minute to remove the toluene remaining in the reactor.

During the oxidation process, the gas was switched to $\mathrm{N}_{2}+$ air $\left(1 \% \mathrm{O}_{2}\right)$ at a flow rate of $1.2 \mathrm{~L} \mathrm{~min}^{-1}$, with high voltage

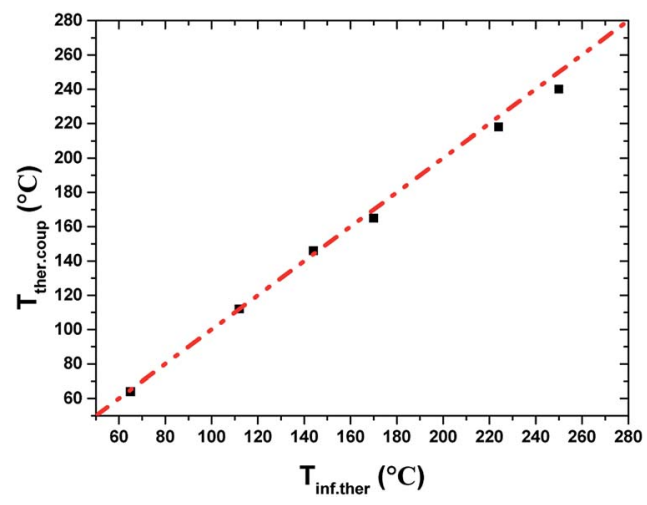

Fig. 5 Comparison of $T_{\text {inf.ther }}$ and $T_{\text {ther.coup }}$ (dotted line represents curve $T_{\text {inf.ther }}=T_{\text {ther.coup }}$ ).

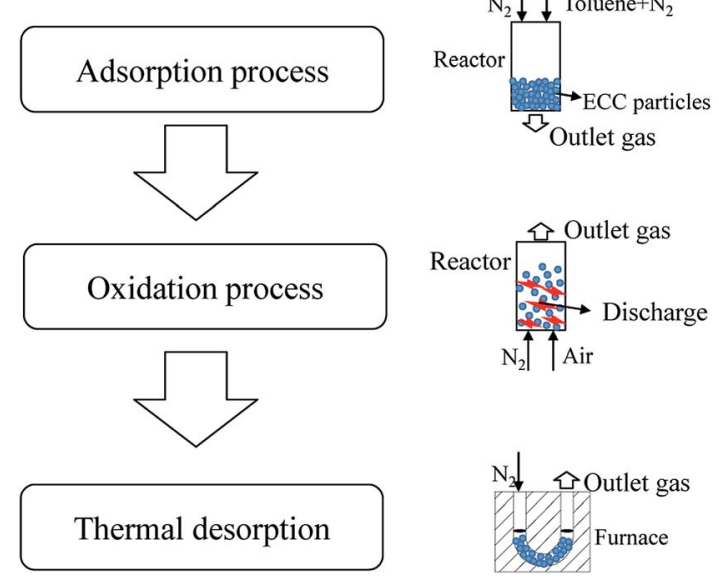

Fig. 6 Experimental procedures. 
applied at the same time. The oxidation process was conducted for $90 \mathrm{~min}$

The toluene concentration at the outlet of the reactor was detected by GC. The gas sampling interval was $\sim 1.4 \mathrm{~min}$ for the initial $10 \mathrm{~min}$, which was increased afterwards ( $\sim 3.8 \mathrm{~min})$, because the desorption rate was higher at the beginning of the process. The toluene concentration curves were integrated, and the amount of toluene was obtained, denoted as $m_{\text {escape }}$.

The remaining particles then underwent thermal desorption (TD) to determine the amount of toluene remaining in the adsorbent. The target desorption temperature was $400{ }^{\circ} \mathrm{C}$, which was increased at a rate of $10^{\circ} \mathrm{C} \mathrm{min}^{-1}$ in $\mathrm{N}_{2}\left(1.2 \mathrm{~L} \mathrm{~min}^{-1}\right)$ and then maintained for $1 \mathrm{~h}$. The remaining toluene was completely desorbed at this temperature. ${ }^{27}$ The toluene concentration was continuously detected by GC so that the amount of toluene remaining in the adsorbent $\left(m_{\text {remain }}\right)$ could be calculated.
Therefore, $m_{\text {decomposed }}$ was calculated by subtraction ( $\left.m_{\text {adsorbed }}-m_{\text {escape }}-m_{\text {remain }}\right)$.

\section{Results and discussion}

\subsection{Discharge characteristics}

Typical voltages, current waveforms and a photo of the discharge are presented in Fig. 7. The waveforms were obtained under an input power of $150 \mathrm{~W}$. The peak-to-peak voltage was $\sim 7 \mathrm{kV}$. Different time scales were chosen to allow for a deeper understanding of discharge characteristics. Voltages and currents changed periodically, following the frequency of the original power source $(50 \mathrm{~Hz})$. Dense current pulses with different amplitudes appeared successively over time, signifying the generation of dense discharge. A single pulse was selected (the dotted-line rectangle in Fig. 7(b)) and described in detail (Fig. 7(a)). When voltage increased to a certain peak value, it
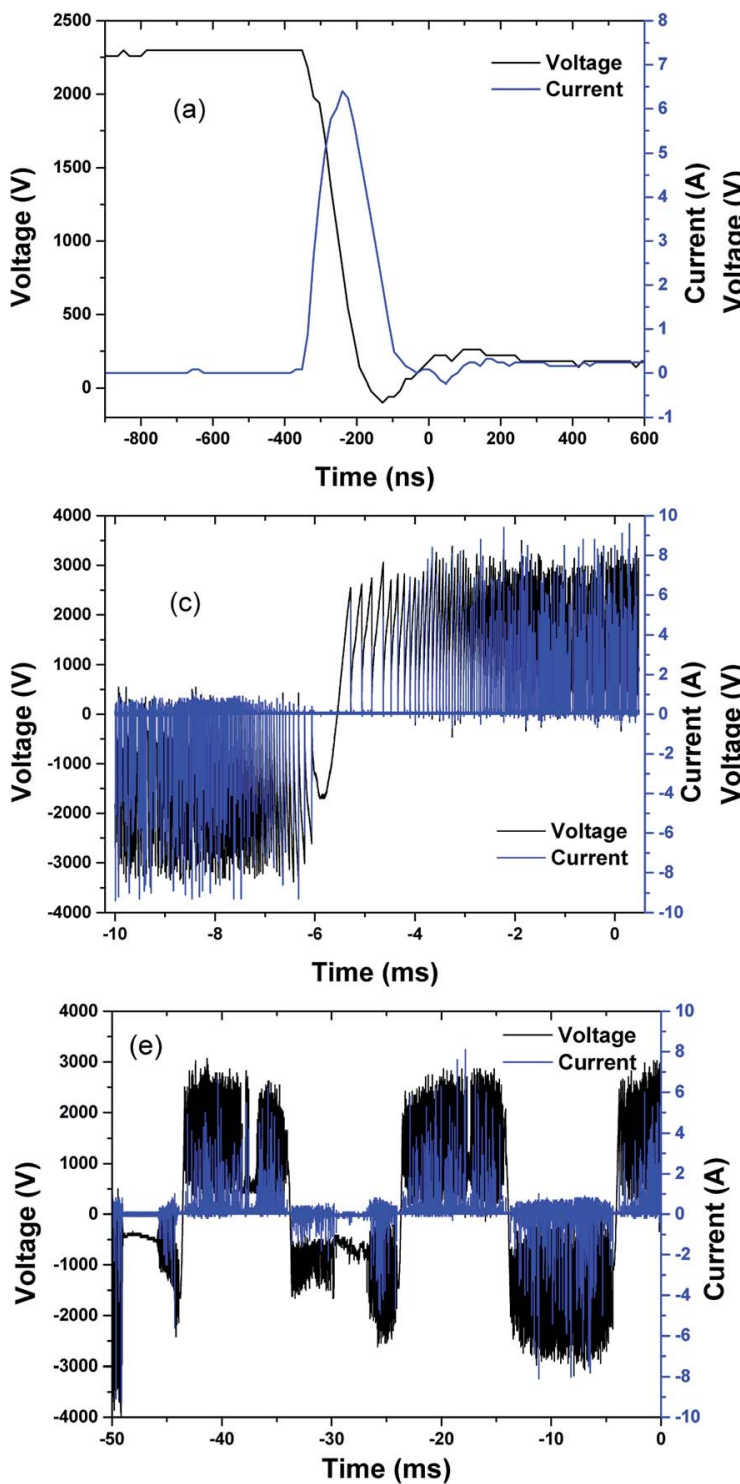
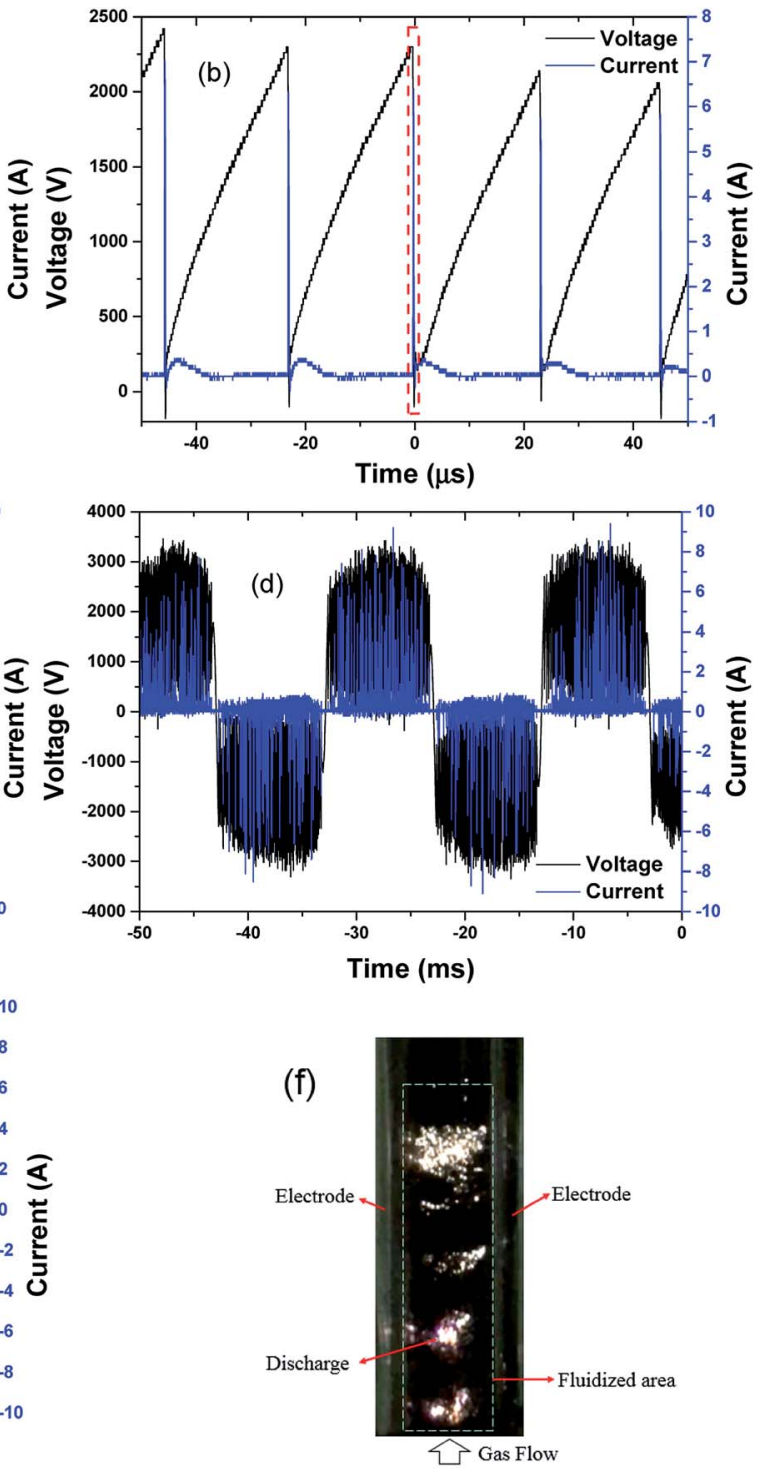

Fig. 7 Typical waveforms of voltage and current (a-e) and a photo (f) of particle-triggered discharge (input power: $150 \mathrm{~W}, \mathrm{gas}$ flow $1.2 \mathrm{~L}$ min ${ }^{-1}$, $1 \% \mathrm{O}_{2}$ ). 

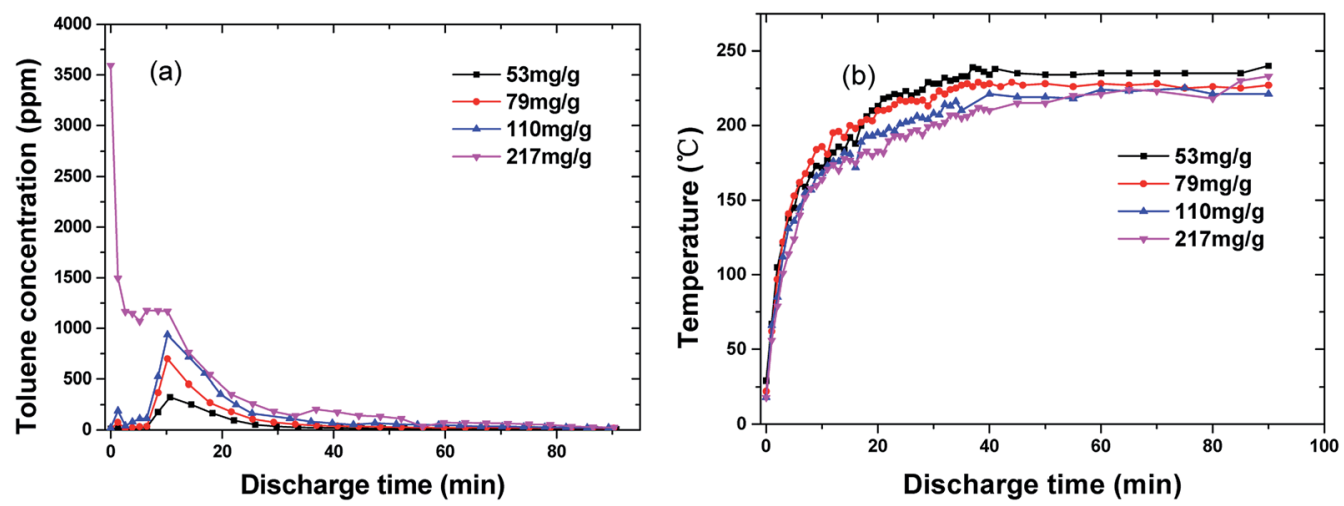

Fig. 8 Toluene concentration at the outlet of reactor (a) and temperature (b) as a function of time under different adsorbed amounts (flow rate: $1.2 \mathrm{~L} \min ^{-1}, 1 \% \mathrm{O}_{2}$, discharge power: $\sim 23 \mathrm{~W}$ ).

dropped abruptly to near-zero, while the current rose up to its maximum value $(\sim 6 \mathrm{~A})$ in less than $200 \mathrm{~ns}$. The maximum current was maintained for about $30 \mathrm{~ns}$ and then decreased to near-zero (Fig. 7(a)) in less than $200 \mathrm{~ns}$. The maximum value of current pulses was $\sim 9 \mathrm{~A}$. These results are typical characteristics of arc discharge, ${ }^{24}$ and each current pulse indicated electrical breakdown. After one pulse, the voltage increased immediately until it reached the next breakdown voltage and led to a new current pulse. As shown in Fig. 7(b), pulses occurred every $23 \mu \mathrm{s}$ (i.e. frequency $\sim 43 \mathrm{kHz}$ ). The frequency of repeated pulses ranged from $\sim 700 \mathrm{~Hz}$ to $50 \mathrm{kHz}$ at different phase angles (Fig. 7(c)). Almost no pulses were formed within a small phase angle $\left(\sim 12^{\circ}\right)$, where a polarity transition occurred. The waveform was occasionally disordered, and current pulses were interrupted irregularly (Fig. 7(e)). The gaps between conductive particles changed arbitrarily due to the turbulence of fluidized particles; thus, arc discharge was distributed randomly within the fluidized volume (Fig. 7(f)).

\subsection{Decomposition characteristics with different adsorption amount}

The adsorption amount was set between $53 \mathrm{mg} \mathrm{g}^{-1}$ and $217 \mathrm{mg} \mathrm{g}^{-1}$. The input power was maintained at $175 \mathrm{~W}$, and the average discharge power was $\sim 23 \mathrm{~W}$. The outlet toluene concentration was presented herein, but no carbon balance analysis was undertaken because the carbon in the adsorbent and toluene were both involved in the reaction process.

Fig. 8 presents the outlet concentration of toluene and the temperature evolution with discharge time under different working conditions. It is notable that there are substantial peaks at $\sim 10 \mathrm{~min}$ after the discharge commenced (except saturated adsorption). The equilibrium temperature of ECC during discharge was $218-235{ }^{\circ} \mathrm{C}$. Fig. 9 compares the outlet concentration of toluene from furnace heating (curve A) and discharge (curve B) at the same maximum temperature $\left(\sim 220^{\circ} \mathrm{C}\right)$ and the same adsorption amount $\left(79 \mathrm{mg} \mathrm{g}^{-1}\right)$. Both the outlet concentrations peaked at around $10 \mathrm{~min}$, indicating that there was a sharp increase in desorption (Fig. 9). Similar results were reported by Mok et al. ${ }^{18}$ and Klett $e t$ al. ${ }^{28}$ The value of curve A was mostly higher than that of curve $\mathrm{B}$, but the desorption rate was calculated to be $\sim 82 \%$ by furnace heating, which is lower than $98 \%$ by discharge $(44.7 \%$ decomposed and $45.3 \%$ escaped). Thus, the arc discharge decomposed toluene and facilitated the desorption of toluene from ECC. ${ }^{29,30}$ It indicates that desorption of toluene was not just due to the thermal effect. Arc discharge may damage a part of the original active sites and weaken the bond between toluene and the adsorbent. This also accords with results in part 3.4, which showed that adsorption capacity decreased after the first oxidation process.
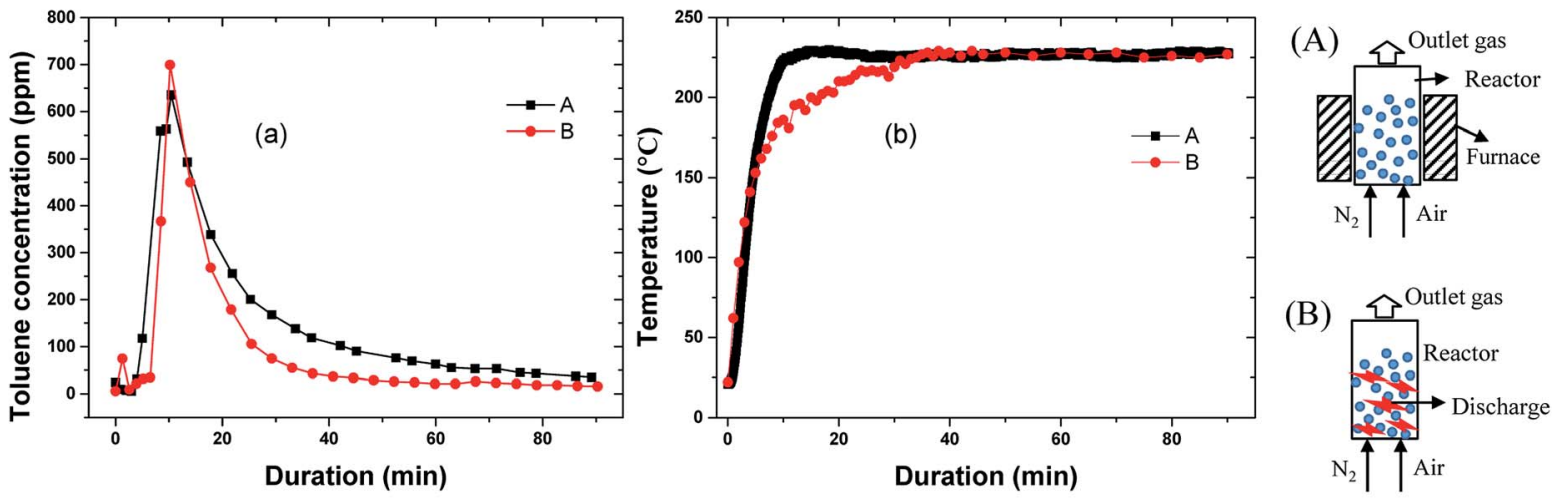

Fig. 9 Comparison of outlet concentrations of toluene (a) at the same maximum temperature (b) (A) by furnace heating, (B) by discharge, maximum temperature: both $\sim 220^{\circ} \mathrm{C}$, adsorption amount: $79 \mathrm{mg} \mathrm{g}^{-1}$, discharge power: $\sim 23 \mathrm{~W}$, flow rate: $1.2 \mathrm{~L} \mathrm{~min}{ }^{-1}, 1 \% \mathrm{O}_{2}$ ). 
Fig. 10 provides an overview of the apportionment of adsorbed toluene under different adsorption amounts. Toluene was almost completely desorbed, with little toluene left in the adsorbent ( $m_{\text {remain }}$ ) (Fig. 10). The figure shows that there was a steady increase in the amount of toluene that escaped in the gas flow ( $\left.m_{\text {escape }}\right)$ and a slight increase in the decomposition capacity $\left(m_{\text {decomposed }}\right)$. The increase in $m_{\text {escape }}$ was evident because the desorption of toluene increased steadily as adsorption increased. The increase in $m_{\text {decomposed }}$, however, was not significant. This was likely because the adsorption amount already covered the decomposition capacity. Background gas was heated by discharge and the temperature increased along the vertical direction. Toluene desorbed more readily at the top of the discharge zone, where there were shorter residence times. This did not make full use of the decomposition capacity. In future upscaling applications, the decomposing capacity might be improved by heat exchange from the upper part to the lower part of the reactor. The oxidation product was collected in a Tedlar gas bag and analysed using FTIR (Nicolet iS50) to determine the oxidation products. The FTIR spectra are shown in Fig. 11. The sample was taken at $20 \mathrm{~min}$ after the discharge commenced. Adsorption peaks were detected for $\mathrm{CO}_{2}, \mathrm{CO}, \mathrm{H}_{2} \mathrm{O}$, $\mathrm{CH}_{4}$, and toluene, ${ }^{18,31,32}$ indicating that decomposed toluene was oxidized into small molecules $\left(\mathrm{CO}_{2}, \mathrm{CO}, \mathrm{H}_{2} \mathrm{O}\right.$ and a small amount of $\left.\mathrm{CH}_{4}\right)$. Almost no ozone or nitrogen oxides were produced in the emitted gas $\left(\mathrm{O}_{3}<0.01 \mathrm{ppm}\right.$ by Ozone Analyzer Monitor 2B 106M, NO < 2 ppm by testo 350).

\subsection{Effect of discharge power}

The input power was set at 100-200 W (corresponding discharge power was 17.4-26.3 W) to investigate the effect of discharge power. The amount of adsorbed toluene kept almost the same $\left(79 \mathrm{mg} \mathrm{g}^{-1}\right)$.

An overview of the toluene apportionment as well as equilibrium temperature is shown in Fig. 12. There was a gradual increase of decomposition efficiency from $24 \%$ to $59 \%$. Increasing discharge power enhanced the generation of energetic electrons while leading to the creation of more reactive species (such as $\mathrm{O}$ radicals). Toluene decomposition was accelerated by the temperature increase, which is confirmed by

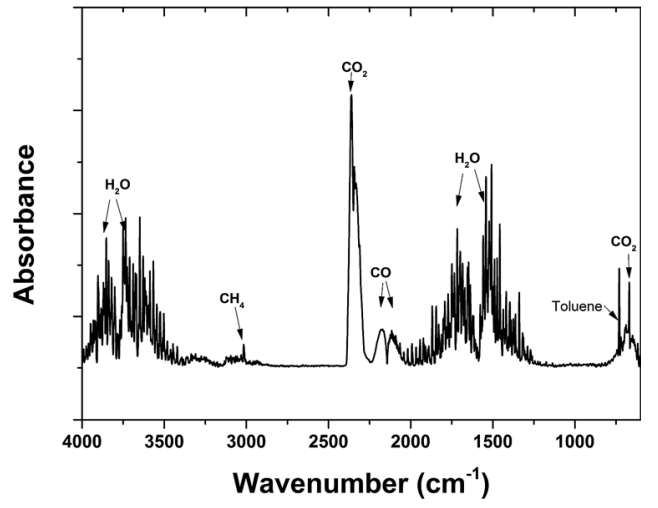

Fig. 11 FTIR spectra of the oxidation products (flow rate: $1.2 \mathrm{~L} \mathrm{~min}^{-1}$, $1 \% \mathrm{O}_{2}$. Adsorbed amount: $217 \mathrm{mg} \mathrm{g}^{-1}$. Input power: $175 \mathrm{~W}$ ).

the inset in Fig. 12. In practical operation, however, a proper discharge power should be selected because the mass loss of the adsorbent increases at higher power.

\subsection{Effect of cyclic utilization on the adsorption capacity}

The objective of this method was to regenerate the adsorbent while decomposing toluene. This is necessary for evaluating adsorption capacity changes after cyclic utilization. Herein, $1 \mathrm{~g}$ of adsorbent was saturated with toluene and used in the oxidation process. After the oxidation process, the residual particles underwent thermal treatment, as introduced in part 2.6. These processes were repeated four times. The input power $(175 \mathrm{~W})$, flow rate $\left(1.2 \mathrm{~L} \mathrm{~min}^{-1}\right)$ and $\mathrm{O}_{2}$ concentration $\left(1 \% \mathrm{O}_{2}\right)$ were kept at the same level. Mass before and after each adsorption process was determined to obtain the adsorption capacity. The adsorption capacities are presented in Fig. 13.

Adsorption capacity continuously increased after an initial decrease from $217 \mathrm{mg} \mathrm{g}^{-1}$ to $203 \mathrm{mg} \mathrm{g}^{-1}$ in the first cycle. The adsorption capacity increased from $203 \mathrm{mg} \mathrm{g}^{-1}$ to $266 \mathrm{mg} \mathrm{g}^{-1}$ after four cyclic treatments.

The micro-morphologies of the adsorbent particles were observed via scanning electron microscopy (SEM) after each cycle (Fig. 14). The surfaces of the original particles were sharp
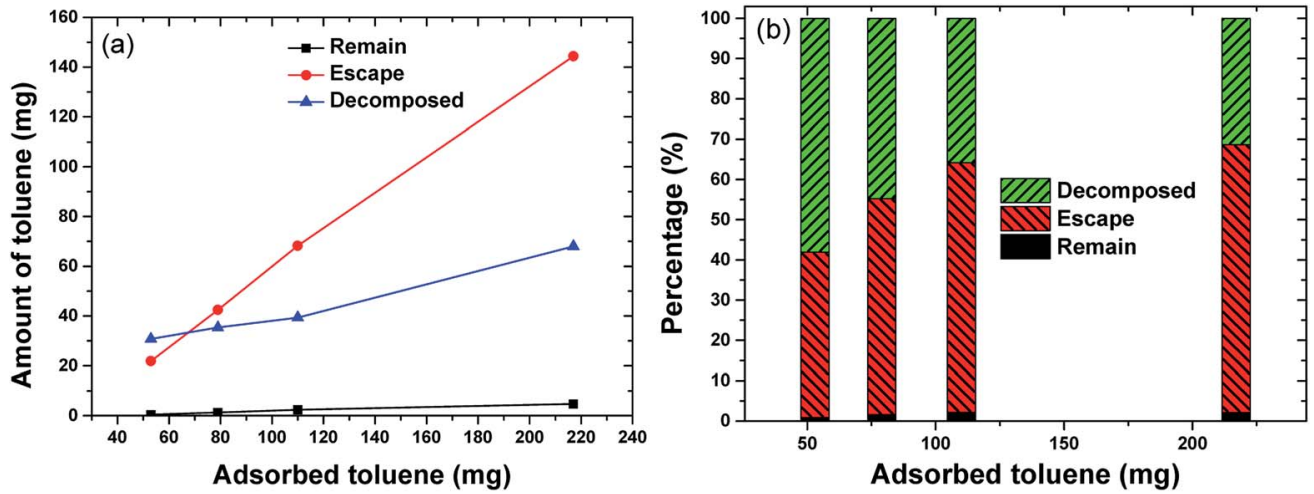

Fig. 10 The apportionment of toluene under different initial adsorbed amounts ((a) toluene amount and discharge power, (b) toluene percentage). 


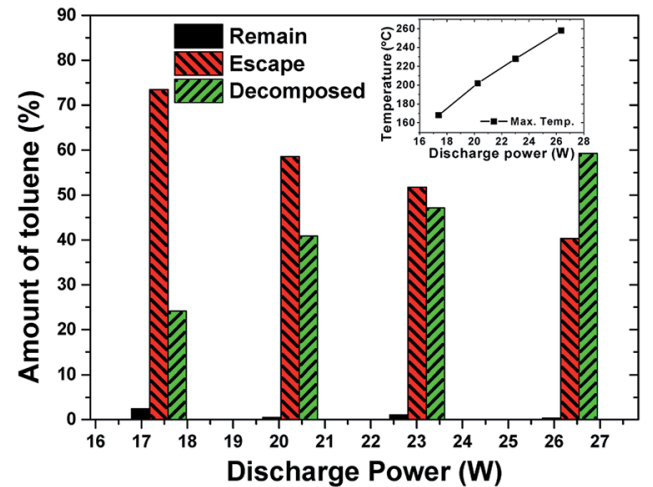

Fig. 12 The apportionment of toluene under different discharge power. (Inset figure: equilibrium temperature. Flow rate: $1.2 \mathrm{~L} \mathrm{~min}^{-1}$, $1 \% \mathrm{O}_{2}$. Adsorbed amount: $79 \mathrm{mg} \mathrm{g}^{-1}$ ).

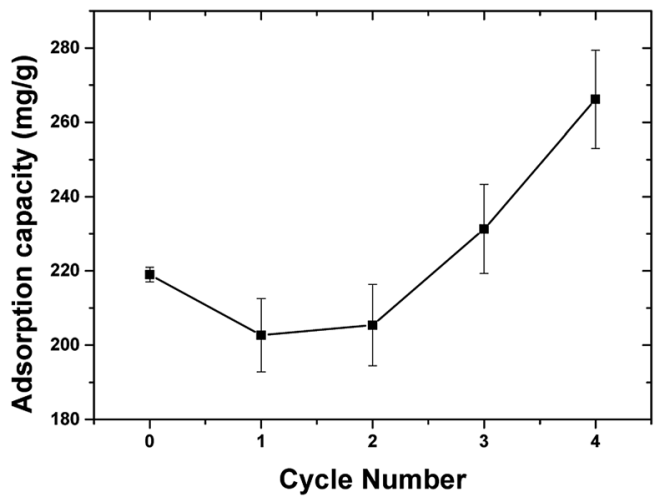

Fig. 13 The adsorption capacity of ECC after each cycle.

with many flake-like structures. After the first cycle, the surface became smooth, indicating the loss of surface fragments. Arc discharge impacted the surface, and the flake-like pieces were easily peeled off. ${ }^{33}$ The pores were likely to have been regenerated (Fig. 14(c-e)) due to the activation of oxygen. ${ }^{34}$ Arc discharge might have led to the destruction of fine particles as well as the activation of the adsorbent.

The mass loss of adsorbents was not negligible. For each cycle, about $15 \%$ of the original mass was lost on average. This is a problem that needs to be solved in further investigations.

\subsection{Design for continuous treatment}

A design for continuous treatment of VOC pollutant and the operating procedure are presented in Fig. 15. The design includes three reactors (R1, R2, and R3). No emissions of VOCs at the effluent gas can be achieved.

(1) The adsorption process starts with R1 (red solid line in Fig. 15(a), A $\rightarrow$ B in Fig. 15(b)), with an adsorption time of $t_{11}$. Before the breakthrough point, adsorption process is switched to $\mathrm{R} 2$ (B $\rightarrow \mathrm{C}$ in Fig. 15(b)), while R1 undergoes an oxidation process (blue line, $\mathrm{B} \rightarrow \mathrm{B}_{1}$ ). At the same time, $\mathrm{R} 3$ undergoes readsorption process (red dotted line I), re-adsorbing the undecomposed VOCs of R2.

(2) The adsorption process was switched back to R1 at point $\mathrm{C}$ in Fig. 15(b). After two re-adsorption processes (B $\rightarrow$ B1, C $\rightarrow$ $\mathrm{C} 1$ in Fig. 15(b)), R3 undergoes an oxidation process (blue line in Fig. 15(a), D $\rightarrow$ D1 in Fig. 15(b)). Moreover, the undecomposed VOC is re-adsorbed by R2 (red dotted line II in Fig. 15(a)). The adsorption period of $\mathrm{R} 2$ (i.e. $t_{21}, \mathrm{E} \rightarrow \mathrm{F}$ in Fig. 15(a)) is shortened due to prior re-adsorption (D $\rightarrow$ D1 in Fig. 15(b)). The processes of $\mathrm{C} \rightarrow \mathrm{F}$ are then repeated.

Referring to the experimental results in part 3.2 , it is supposed that toluene is the only VOC pollutant, and the discharge power $\left(P_{\text {discharge }}\right)$ is $23 \mathrm{~W}$. Each reactor contains $1 \mathrm{~g}$ of ECC. The oxidation process is conducted for $90 \mathrm{~min}\left(t_{2}\right)$. The adsorption amount $\left(m_{\mathrm{a}}\right)$ is $79 \mathrm{mg}$ each time for each reactor. The decomposition efficiency $(\eta)$ is $60 \%$. The remaining toluene in the adsorbent was neglected after each oxidation process. Since this method aims to treat low concentration VOCs pollutant, the concentration of toluene $\left(C_{\mathrm{t}}\right)$ was set at $10 \mathrm{ppm}$, with a flow rate $(F)$ of $1.2 \mathrm{~L} \mathrm{~min}^{-1}$.
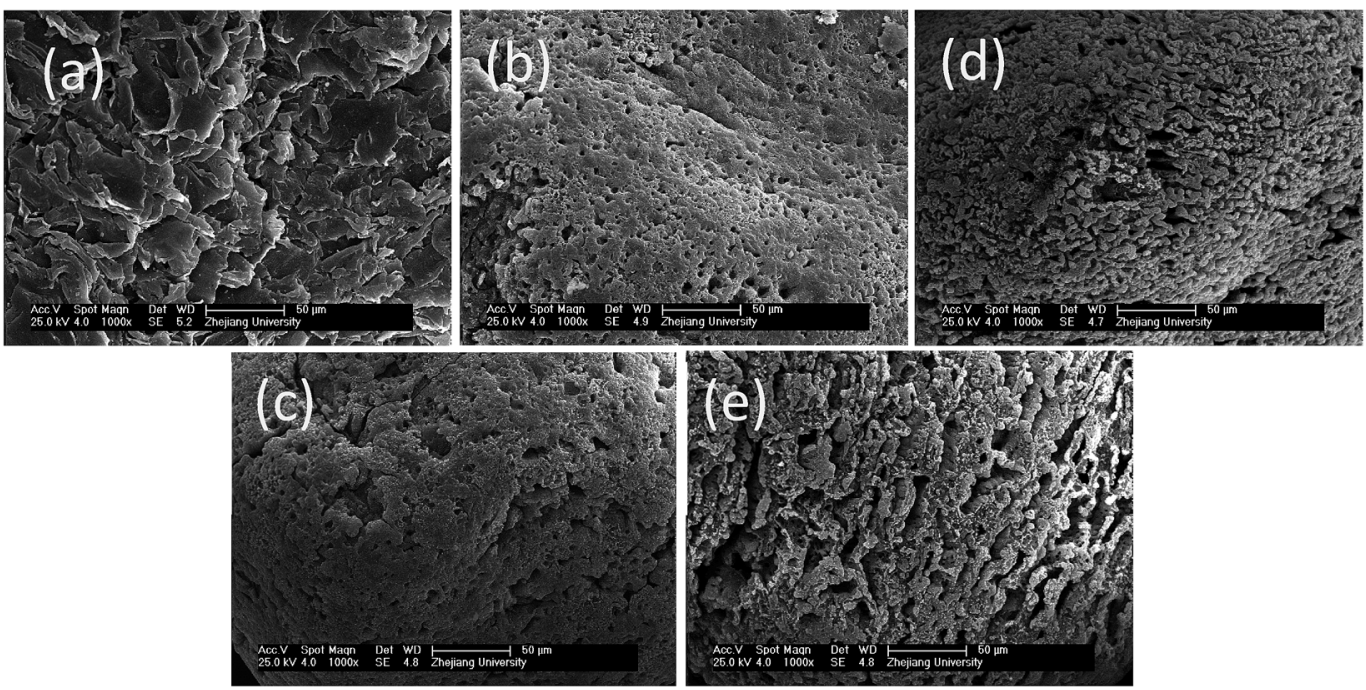

Fig. 14 SEM images from before and after each cyclic oxidation stage ((a) primary ECC, (b-e) $1^{\text {st }}-4^{\text {th }}$ cycle). 

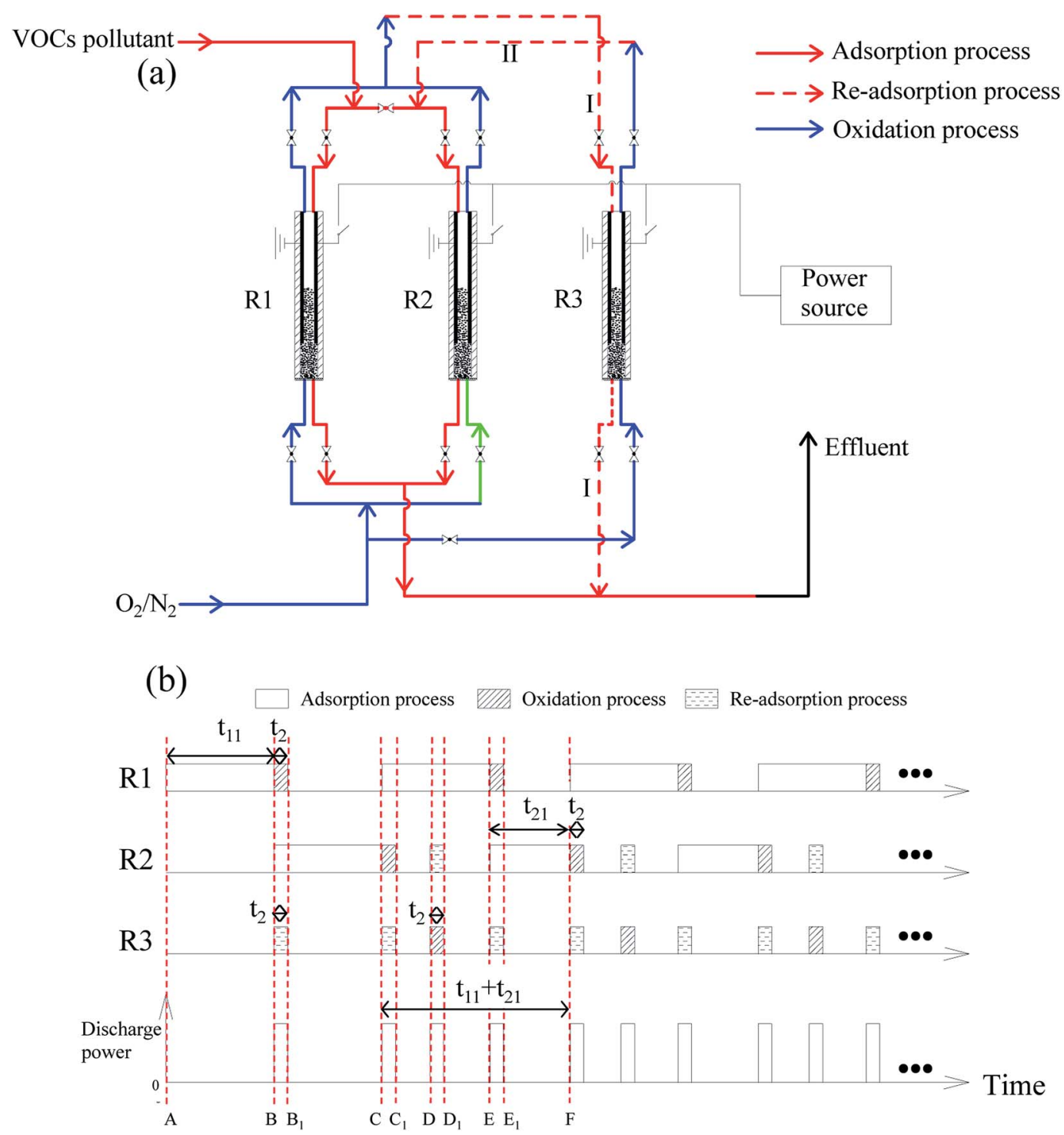

Fig. 15 Design of continuously treatment of VOC pollutant (a) and the operating procedure (b).

In every period of $\left(t_{11}+t_{21}\right)$, three oxidation stages are conducted (Fig. 15(b)). The average energy cost (EC) could be calculated by eqn (1):

$$
\mathrm{EC}=\frac{P_{\text {discharge }} \times 3 t_{2}}{F\left(t_{11}+t_{21}\right)}
$$

where $t_{11}$ and $t_{21}$ are the adsorption time (min) of R1 and R2, respectively. They are calculated by eqn (2) and (3).

$$
\begin{gathered}
t_{11}=\frac{m_{\mathrm{a}} \times 22.14 \times 10^{3}}{\mathrm{MFC}_{\mathrm{t}}} \\
t_{21}=\frac{\left[m_{\mathrm{a}}-2(1-\eta) m_{\mathrm{a}}(1-\eta)\right] \times 22.14 \times 10^{3}}{\operatorname{MFC}_{\mathrm{t}}}
\end{gathered}
$$

It can be calculated that $t_{11}=1582 \mathrm{~min}$ and $t_{21}=1076 \mathrm{~min}$. Overall discharge time covers $\sim 10 \%$ of the total treatment time on average. The average energy cost is $0.032 \mathrm{~kW} \mathrm{~h} \mathrm{~m}^{3}$. Since mass loss of ECC was $\sim 15 \%$ in each oxidation process, $1 \mathrm{~g}$ of virgin adsorbent needs to be replenished every $5907 \mathrm{~min}$ on average. Further investigation is needed to optimize the energy cost and reduce the adsorbent loss.

\section{Conclusions}

A new approach for toluene decomposition and adsorbent regeneration based on ECC particle-triggered discharge was investigated. This study identified the influences on the apportionment of adsorbed toluene and adsorption capacity change. The following conclusions were obtained:

The arc discharge decomposed toluene and facilitated the desorption of toluene from ECC. Almost $60 \%$ of toluene was decomposed at one time under experimental conditions. An increase in the initial adsorption amount and discharge power benefitted the decomposition capacity, but the former was limited due to insufficient residence time. Almost no ozone or 
nitrogen oxides were produced in the gas product. The adsorption capacity increased by $16.4 \%$ after four storagedischarge process cycles. Using three reactors, a design for continuous treatment without the emission of VOCs was presented.

\section{Conflicts of interest}

There are no conflicts to declare.

\section{Acknowledgements}

The authors gratefully acknowledge the support from the National Natural Science Foundation of China (No. 51276167).

\section{References}

1 A. M. Vandenbroucke, R. Morent, N. De Geyter and C. Leys, J. Hazard. Mater., 2011, 195, 30-54.

2 J. Cao, J. Earth Environ., 2012, 3, 1030-1036.

3 C. N. E. M. Centre, Air Quality Report in 74 Chinese Cities in January 2017 (in Chinese), accessed 27 February, 2017.

4 G. Xiao, R. Xiao, B. S. Jin, W. Zuo, J. C. Liu and J. R. Grace, J. Biobased Mater. Bioenergy, 2010, 4, 426-429.

5 N. D. R. Commission, the 13th Five-Year Plan for Economic and Social Development of the People's Republic of China (in Chinese), accessed 16 March, 2016.

6 X. Liang, X. Chen, J. Zhang, T. Shi, X. Sun, L. Fan, L. Wang and D. Ye, Atmos. Environ., 2017, 162, 115-126.

7 R. Wu and S. Xie, Environ. Sci. Technol., 2017, 51, 2574-2583.

8 C. Subrahmanyam, A. Renken and L. Kiwi-Minsker, Chem. Eng. J., 2007, 134, 78-83.

9 R. Huang, M. Lu, P. Wang, Y. Chen, J. Wu, M. Fu, L. Chen and D. Ye, RSC Adv., 2015, 5, 72113-72120.

10 W. Xu, X. Xu, J. Wu, M. Fu, L. Chen, N. Wang, H. Xiao, X. Chen and D. Ye, RSC Adv., 2016, 6, 104104-104111.

11 A. Indarto, D. R. Yang, C. H. Azhari, W. H. W. Mohtar, J.-W. Choi, H. Lee and H. K. Song, Chem. Eng. J., 2007, 131, 337-341.

12 T. Nunnally, A. Tsangaris, A. Rabinovich, G. Nirenberg, I. Chernets and A. Fridman, Int. J. Hydrogen Energy, 2014, 39, 11976-11989.

13 M. J. Kirkpatrick, W. C. Finney and B. R. Locke, Catal. Today, 2004, 89, 117-126.
14 J. Van Durme, J. Dewulf, W. Sysmans, C. Leys and H. Van Langenhove, Chemosphere, 2007, 68, 1821-1829.

15 J. Xi, J. Wu, H. Hu and G. Wang, China Environ. Sci., 2012, 32, 1955-1960.

16 X. Dang, J. Huang, L. Cao and Y. Zhou, Catal. Commun., 2013, 40, 116-119.

17 T. Kuroki, K. Hirai, R. Kawabata, M. Okubo and T. Yamamoto, IEEE Trans. Ind. Appl., 2010, 46, 672-679.

18 Y. Mok and D. Kim, Curr. Appl. Phys., 2011, 11, S58-S62.

19 T. Ohshima, T. Kondo, N. Kitajima and M. Sato, IEEE Trans. Ind. Appl., 2010, 46, 23-28.

20 L. Sivachandiran, F. Thevenet, P. Gravejat and A. Rousseau, Chem. Eng. J., 2013, 214, 17-26.

21 D.-Z. Zhao, X.-S. Li, C. Shi, H.-Y. Fan and A.-M. Zhu, Chem. Eng. Sci., 2011, 66, 3922-3929.

22 Z. Machala, E. Marode, M. Morvová and P. Lukáč, Plasma Processes Polym., 2005, 2, 152-161.

23 W. Mista and R. Kacprzyk, Catal. Today, 2008, 137, 345-349.

24 Y. P. Raizer and J. E. Allen, Gas discharge physics, Springer, Berlin, 1997.

25 G. Xiao, M. Ni, R. Xiao, X. Gao and K. Cen, J. Biobased Mater. Bioenergy, 2012, 6, 69-74.

26 NIST Chemistry WebBook, http://webbook.nist.gov/ chemistry/, accessed 21 March, 2017.

27 F. J. Maldonado-Hódar, C. Moreno-Castilla, F. CarrascoMarín and A. F. Pérez-Cadenas, J. Hazard. Mater., 2007, 148, 548-552.

28 C. Klett, X. Duten, S. Tieng, S. Touchard, P. Jestin, K. Hassouni and A. Vega-González, J. Hazard. Mater., 2014, 279, 356-364.

29 N. Blin-Simiand, P. Tardiveau, A. Risacher, F. Jorand and S. Pasquiers, Plasma Processes Polym., 2005, 2, 256-262.

30 V. I. Pârvulescu, M. Magureanu and P. Lukes, Plasma chemistry and catalysis in gases and liquids, John Wiley \& Sons, 2012.

31 D.-Z. Zhao, X.-S. Li, C. Shi, H.-Y. Fan and A.-M. Zhu, Chem. Eng. Sci., 2011, 66, 3922-3929.

32 Y.-H. Song, S.-J. Kim, K.-I. Choi and T. Yamamoto, J. Electrost., 2002, 55, 189-201.

33 Y.-F. Guo, D.-Q. Ye, K.-F. Chen, J.-C. He and W.-L. Chen, J. Mol. Catal. A: Chem., 2006, 245, 93-100.

34 S. Tang, N. Lu, J. K. Wang, S.-K. Ryu and H.-S. Choi, J. Phys. Chem. C, 2007, 111, 1820-1829. 